\title{
Psychedelic therapy in the Czech Republic: A theoretical concept or a realistic goal?
}

\author{
ZUZANA POSTRÁNECKÁ ${ }^{1 *}$, ČESTMÍR VEJMOLA ${ }^{1,2,3}$ and FILIP TYLS̆ $\check{L}^{1,2,3}$ \\ ${ }^{1}$ Czech Psychedelic Society, Klecany, Czech Republic \\ ${ }^{2}$ National Institute of Mental Health, Klecany, Czech Republic \\ ${ }^{3} 3$ rd Medical Faculty, Charles University in Prague, Prague, Czech Republic
}

(Received: October 9, 2018; accepted: December 13, 2018)

\begin{abstract}
Psychedelic research has been associated with the Czech Republic since the early 19th century and, after a long period of involuntary dormancy, it has recently gained new opportunities to follow up on its roots and evolve. This article briefly describes the history of psychedelic research in the Czech Republic, summarizes the role of the UN Drug Conventions, and discusses the Czech and international legislation pertaining to psychedelics. The discussion focuses on the dependence/abuse potential of classical psychedelics, their medical use, and their safety in medical versus non-medical environment. Despite the assertions of the $\mathrm{UN}$ and occasional media disinformation about the dangers of psychedelics, recent investigations have shown that classical psychedelics are not addictive, show great promise in a broad spectrum of medical uses, and have been repeatedly proven to be safe in a clinical setting. Finally, the authors suggest a procedure for the preparation and implementation of controlled psychedelic therapy in the Czech medical and legal system.
\end{abstract}

Keywords: psychedelics, abuse, dependence, addiction, drug legislation

\section{INTRODUCTION}

The so-called classical psychedelics, or serotonergic hallucinogens, include mainly lysergic acid diethylamide (LSD), psilocybin, mescaline, dimethyltryptamine (DMT), and methoxy-N,N-dimethyltryptamine (5-MeO-DMT). Serotonergic hallucinogens are a subgroup of three classes of compounds: tryptamines, ergolines, and phenethylamines, of which the latter group also includes the so-called entactogens/empathogens (MDMA or 2C-B). In a broader context, the hallucinogen class could also include a selective kappa-opioid agonist salvinorin A found in Salvia divinorum, dissociative anesthetics (ketamine), cholinergic delirogens (tropane alkaloids and their plant sources such as datura or deadly nightshade), and sometimes also cannabis (marijuana and hashish). This article only discusses serotonergic hallucinogens, which will be referred to as psychedelics.

Naturally occurring psychedelics have been associated with various human societies since time immemorial. The ritual use of psychedelics has been preserved to the present times mostly in native South American tribes, typically in various naturally occurring forms (DMT in the hallucinogenic brew ayahuasca, psilocybin in magic mushrooms, mescaline in cacti, 5-MeO-DMT in the venom of hallucinogenic toads). The discovery of psychedelics by Western society in the 20th century sparked a surge of extensive research, mainly due to their potential in the treatment of psychiatric disorders, which showed great promise (Tylš, Páleníček, \& Horáček, 2014).
During that time, the Czech Republic was one of the focal points of psychedelic research. First self-experiments with psychotropic substances were conducted and later reported by Purkyně in early 19th century, namely with the deadly nightshade, nutmeg, opium, and other substances. In 1947, psychiatrist Světozar Nevole published a book recounting his experiences with peyote and its ability to expand consciousness, significantly inspiring many other Czech physicians including Stanislav Grof [American psychiatrist born in Prague, founder of transpersonal psychology. With his wife Christina, he developed the Holotropic Breathwork method and wrote several books about spiritual emergency. His famous works include LSD Psychotherapy (1980) or The Cosmic Game: Explorations of the Frontiers of Human Consciousness (1998)] or Milan Hausner (Czech psychiatrist who administered LSD to patients as part of psychotherapy in a psychiatric hospital in Sadská in the 1970s. He wrote a book named LSD: The Highway to Mental Health with Erna Segal; Winkler \& Csémy, 2014). In addition, psychiatrist Roubíček (1961) started to self-experiment with LSD shortly after its discovery by Albert Hofmann. Psychedelic therapy in the Czech Republic started in 1954 and ended in 1974, making the country one of the very last to introduce the spreading ban on psychedelics, which effectively halted the research for many years. The main research sites included the Psychiatric Hospital in

* Corresponding author: Zuzana Postránecká; Czech Psychedelic Society, Topolová 748, CZ-250 67 Klecany, Czech Republic; Phone: +420 7756 24364; E-mail: postraneckaz@seznam.cz

This is an open-access article distributed under the terms of the Creative Commons Attribution-NonCommercial 4.0 International License, which permits unrestricted use, distribution, and reproduction in any medium for non-commercial purposes, provided the original author and source are credited, a link to the CC License is provided, and changes - if any - are indicated. 
Sadská near Poděbrady and the Psychiatric Research Institute in Prague. In these institutions, hundreds of research subject underwent psycholytic and psychedelic therapy and Dr. Hausner personally conducted over 3,000 psychedelic sessions in the Sadská Hospital. Self-experimentation with psychedelics was an official part of psychedelic-assisted psychotherapy training, requiring five controlled LSD (or occasionally psilocybin) intoxications (Hausner \& Segal, 2016).

In the 1960s, psychedelics started to gain significant popularity among the general public, mainly in the USA, and brought about a surge of panic in the rigid society of the time also due to their ability to affect the individual's value system. Politically motivated prohibition, the so-called War on Drugs [The War on Drugs was another unsuccessful prohibition campaign (Austin \& McVey, 1989; Blocker, 2006), directed against an inanimate object that has no agency of its own.], supported by the media, gradually led to a worldwide ban on selected psychedelics. During the entire duration of the ban, psychedelics were widely used by the alternative culture with relatively minimal negative effects on mental health (Krebs \& Johansen, 2013).

In the scientific community, however, the discussion of the potential uses of psychedelics in the treatment of a broad spectrum of psychiatric disorder has been gaining more and more attention - from depression, post-traumatic stress disorder and obsessive-compulsive disorder (OCD) to addictions. Furthermore, psychedelics can be used as a tool for the study of severe psychiatric illnesses such as schizophrenia (Geyer \& Vollenweider, 2008) or the unconscious processes that underlie various neurotic spectrum disorders (Viktorinová \& Tylš, 2016). The Czech Republic remains in the forefront of psychedelic science even today - the Czech National Institute of Mental Health is currently conducting a clinical trial on psilocybin as a model of psychosis. To date, psilocybin has been administered to 20 healthy volunteers (Bravermanová et al., 2018). Moreover, a new multicenter research sponsored by Compass Pathways will study the use of psilocybin in a new sample of patients with treatment-resistant depression.

This review focuses on the legal, social, and medical status of psychedelics in research and therapy in the Czech context, aiming to illustrate the dysfunctional nature of the contemporary system of substance control and to reevaluate the current legislative position of psychedelics in light of the most recent scientific findings. Its goals include opening the discussion on the possibility of facilitating new psychedelic research and helping it reach the depths it needs to present the therapeutic and self-developmental potential of these substances to the professional public.

\section{CURRENT POSITION OF PSYCHEDELICS IN THE CZECH REPUBLIC}

The Parties, Being concerned with the health and welfare of mankind, Noting with concern the public health and social problems resulting from the abuse of certain psychotropic substances, Determined to prevent and combat abuse of such substances and the illicit traffic to which it gives rise, Considering that rigorous measures are necessary to restrict the use of such substances to legitimate purposes, Recognizing that the use of psychotropic substances for medical and scientific purposes is indispensable and that their availability for such purposes should not be unduly restricted, (...) (Preamble to the Convention on Psychotropic Substances, 1971)

The Code of Ethics of the Czech Medical Chamber instructs physicians that they should freely choose and perform preventative, diagnostic, and therapeutic procedures that comply with the present state of medical science and that they consider appropriate for the patient, in accordance with their professional qualification and competence (provisions of Section 2 of the professional directive of the Czech Medical Chamber - The Code of Ethics of the Czech Medical Chamber). The Charter of Fundamental Rights and Freedoms, one of the cornerstones of the Czech legal system, guarantees the freedom of scholarly research (Article 15 of the Constitutional Act No. 2/1993 Coll. as amended by Constitutional Act No. 162/1998 Coll.). The authors of this paper are of the opinion that it is necessary to update the current legal framework, which reflects a stigmatized approach toward psychedelics, because recent studies have shown that psychedelics have a positive effect on patients with certain psychiatric disorders, particularly in cases where other treatment modalities fail. The current legal framework hampers the introduction of psychedelics into medicine in various direct and indirect ways.

As a member of the UN, the Czech Republic is bound as any other UN countries by three conventions - Single Convention on Narcotic Drugs, 1961; Convention on psychotropic substances, 1971; and Convention Against Illicit Traffic in Narcotic Drugs and Psychotropic Substances from 1988 (Figure 1). These conventions also govern all member states of the European Union and the list of substances includes four basic groups divided according to their safety and therapeutic utility. Classical psychedelics are listed in Schedule 1, which is, according to the UN Commission on Narcotics, defined as a group of substances that pose a great risk to society and have no therapeutic potential. Despite this claim, certain UN member countries have successfully used Schedule 1 substances in research and therapy [Czech Republic (LSD; e.g., Crockford, 2007), Switzerland (MDMA, LSD, psilocybin, 2C-B; e.g., Fischer, 2015), UK (psilocybin; e.g., Carhart-Harris et al., 2016), Peru, Columbia, Brazil [ayahuasca, used for thousands of years by shamans as medicine for various ailments, has been recognized as the cultural heritage of Peru and Columbia, and its use within the shamanic practice is therefore protected by the state. Later, Brazil permitted the use of ayahuasca to the practitioners of two religions: Santo Daime and União de Vegetal (Kavenská \& Simonová, 2014)], USA [psilocybin; e.g., - (a) Bogenschutz et al., 2015; (b) Grob et al., 2011; (c) Johnson, Garcia-Romeu, Cosimano, \& Griffiths, 2014; MDMA, e.g., Mithoefer, Wagner, Mithoefer, Jerome, \& Doblin, 2011; complete history of the use of psychedelics in psychotherapy from 1931 to 1995 in Passie, 1997], introduced decriminalization and controlled sales [Netherlands 


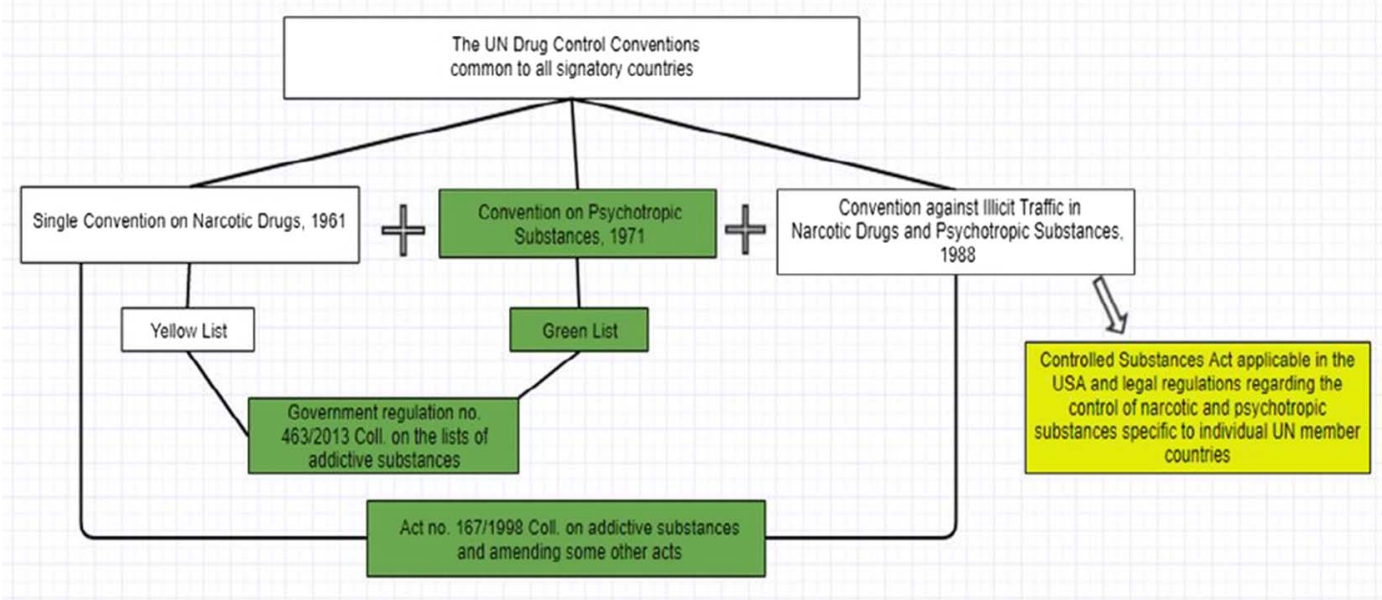

Figure 1. International UN conventions on narcotic and psychotropic substances and their relation to the drug laws in the Czech Republic and elsewhere. Green color boxes represent conventions, laws, and regulations that are directly related to psychedelics, and yellow box the laws that are directly related to psychedelics, stem from the UN conventions on narcotic and psychotropic substances, but do not affect Czech drug

legislation. The yellow list, accompanying the Single Convention on Narcotic Drugs, contains the current list of controlled narcotic substances, and the green list, which is based on the Convention on Psychotropic Substances, contains the up-to-date list of controlled psychotropic substances

(https://www.government.nl/topics/drugs/contents/tolerationpolicy-regarding-soft-drugs-and-coffee-shops), Spain, Sri Lanka, and Uruguay] and some have even legalized these substances for medical [Marijuana legalized for medicinal use - Argentina, certain Australian states, Canada, Chile, Colombia, Croatia, Cyprus, Czech Republic, Denmark, Finland, Germany, Greece, Israel, Italy, Jamaica, Luxembourg, Malta, Macedonia, Netherlands, Norway, Peru, Poland, Portugal, Puerto Rico, San Marino, South Africa, Spain, Sri Lanka, Switzerland, Turkey, UK, Uruguay, certain states in the USA, Vanuatu, Zimbabwe (as of November 27, 2018)] as well as recreational use [The recreational use and the possession of marijuana for personal use is legal or decriminalized - either completely or below specific quantities - in Antigua and Barbuda, Argentina, certain states or territories of Australia, Austria, Belgium, Belize, Bolivia, Brazil, Canada, Chile, Costa Rica, Croatia, Czech Republic, Ecuador, Estonia, Georgia, certain states of India, Italy, Jamaica, Luxembourg, Malta, Mexico, Moldova, Netherlands, Paraguay, Peru, Portugal, Russia, Uruguay, Slovenia, South Africa, Spain, Sri Lanka, Switzerland, Columbia, and certain states and cities in the USA (as of November 27, 2018).], since the time these conventions came into effect.

Even though Schedule 1 substances from the Convention on psychotropic substances are considered the most strictly controlled, they still should be available for medical and research purposes as the convention itself in Article 7, stipulates a unified regulatory framework, which among other things includes a recommendation for member states to prohibit all use except for scientific and very limited medical purposes by duly authorized persons, in medical or scientific establishments which are directly under the control of their Governments or specifically approved by them (https://www.unodc.org/pdf/convention_1971_en.pdf, p. 6). In the Czech Republic, this issue is further covered by the Government Regulation 463/2013 Coll. on the lists of addictive substances (the "Government Regulation on Addictive Substances"), which classifies DMT, LSD, MDMA, psilocybin, and others into List no. 4, which is equivalent to the aforementioned Schedule 1 of the UN Convention on Psychotropic Substances and the US Controlled Substances Act (Figure 2; http://www.fda.gov/regulatoryinformation/ legislation/ucm $148726 . \mathrm{htm})$. It stipulates that these substances should only be "used for limited purposes of research and science and very limited therapeutic purposes specified in the handling permit" (https://www.zakonyprolidi.cz/cs/ 2013-463\#f5150334). However, this benevolence has its limits, as determined by the Ministry of Health, which issues the authorization for the production, import, export, and handling of narcotic and psychotropic substances, and by the State Institute for Drug Control, which is authorized to issue certificates confirming compliance with good manufacture practice (GMP) standards [GMP is a quality management system in pharmaceutical manufacturing. It works to protect the consumer market from medicinal products, which are of unsatisfactory quality or are not suitable for the intended application. Legislative framework: Act no. 79/1997 Coll. as amended by Act no. 269/2003 Coll. as subsequently amended; Directives 2003/94/EC, 2004/27/ EC and 2004/28/EC; ICH Q7 guidelines (for EU, USA, and Japan). GMP guidelines are detailed in the Ordinance of the Ministry of Health no. 411/2004 Coll. and the EU document "Good Manufacturing Practice" in Volume 4 of the rules governing medicinal products in the European Union (Czech translation in SÚKL Directive VYR-32 published in Věstník SÚKL č. 2/2006)], good distribution practice, good clinical practice, good pharmaceutical practice, and good practice of restricted medicine sales.

Due to numerous legislative and administrative setbacks that impede the research of psychedelics and the tendency to demonize these substances in Europe and elsewhere in the world, the scientific community often lacks the pharmaceutical dosage forms necessary for research and therapy. 


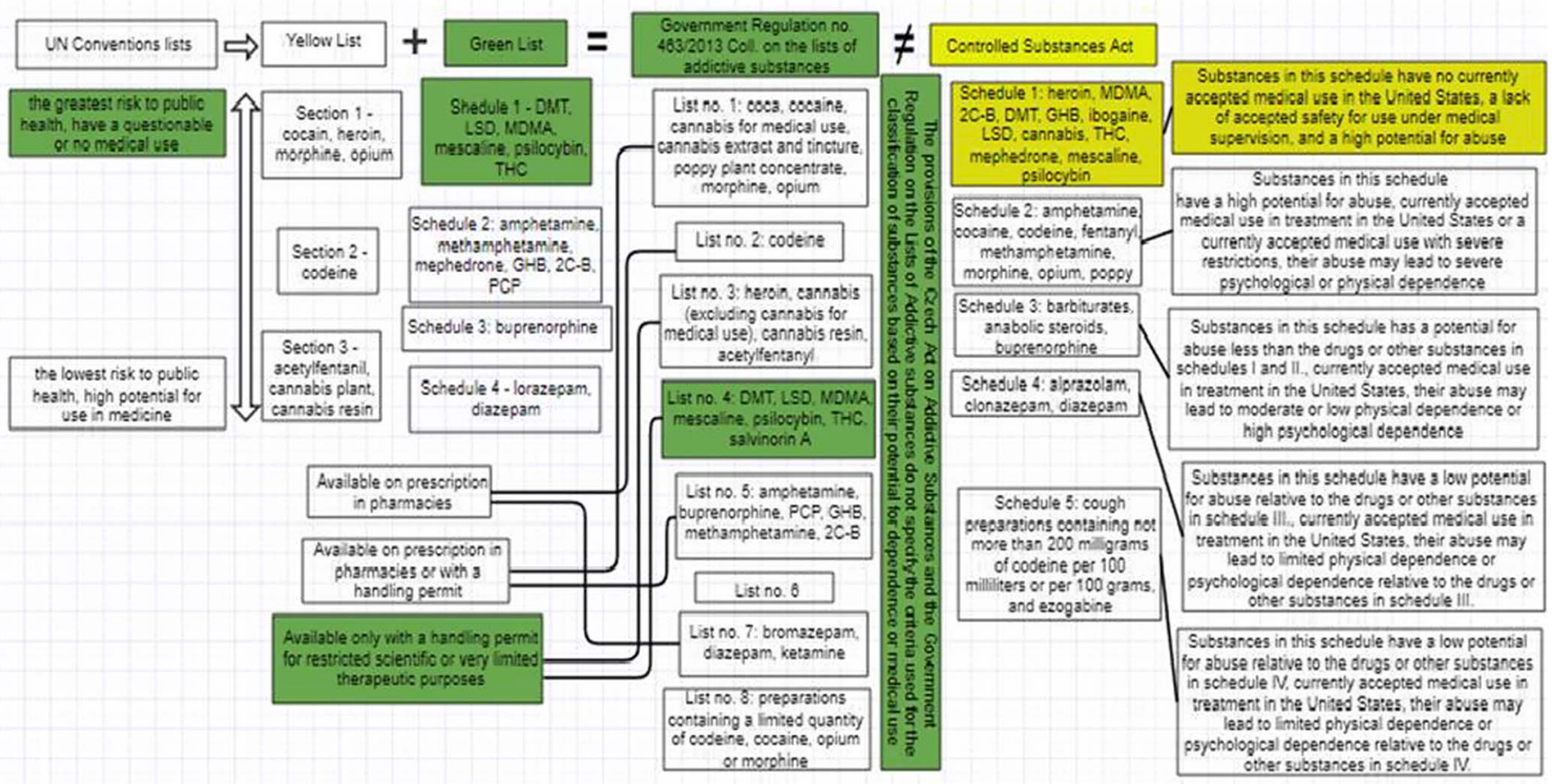

Figure 2. Conventions, laws and regulations that contain lists of narcotic and psychotropic substances. Green color boxes represent regulations that are directly related to psychedelics, yellow boxes the laws and their segments that are directly related to psychedelics but do not affect Czech drug legislation. The Government Regulation no. 463/2013 Coll. contains the lists of narcotic and psychotropic substances and comprises the yellow list and the green list, which reflect international drugs conventions. The US Controlled Substances Act is also based on international conventions and it contains substance lists and applicable laws that govern the handling of controlled substances. It

also provides the rationale for substance scheduling. However, this system is not applicable or enforceable in the Czech Republic

Apart from the psychotropic substances handling permit (conditions for applicants are listed in Sections 4, 8, and 9 of Act no. 167/1998 Coll. on addictive substances as amended; hereinafter the "Act on Addictive Substances"), which is fully dependent on the decision of the Ministry of Health and is not legally enforceable (Section 8, paragraph 1 of the aforementioned act), the sponsor also needs to procure a supplier with the same permit, willing to manufacture the given substance for the purposes of the research. Moreover, the manufacturer is also required to have a certificate on GMPs for narcotic and psychotropic drugs issued by the Czech Institute for Drug Control. At this point, there is no such manufacturer for classical psychedelics in the Czech Republic (negotiations with potential manufacturers located in the Czech Republic are currently underway.). At present, the only way to obtain a psychedelic substance for a research project is to import it from another country that manufactures. Each individual import of Group 4 substances also requires an authorization by the Ministry of Health based on the provisions of Section 22 of the Act on Addictive Substances. Import of course substantially increases the price of the preparation and research costs in general.

\section{CRITICAL REVIEW OF THE ACT ON CONTROLLED SUBSTANCES}

Most classical psychedelics were scheduled as controlled substances in 1971 via the UN Convention on Psychotropic
Substances (https://en.wikisource.org/wiki/Convention_on_ Psychotropic_Substances\#Article_2). The criteria for including these substances into Schedule 1 are not provided in the convention itself nor in the so-called Green List (https:// www.incb.org/documents/Psychotropics/greenlist/2016/ V1604744_Eng.pdf) (the document that lists controlled substances that are subject to the aforementioned law). The Convention on Psychotropic Substances only proposes conditions under which other substances should be included in the list or reviewed by the World Health Organization (WHO). These conditions are as follows:

- capacity to produce dependence;

- capacity to produce central nervous system stimulation or depression, resulting in hallucinations or disturbances in motor function or thinking or behavior or perception or mood;

- capacity to produce similar abuse and similar ill effects as a substance in Schedules I, II, III, or IV; and

- sufficient evidence that the substance is being or is likely to be abused so as to constitute a public health and social problem.

The Czech Act on Addictive Substances (https://www. zakonyprolidi.cz/cs/1998-167) has implemented the international UN conventions as amended, also considering the EU Drugs Strategy and WHO plans. The provisions of this act or the Government Regulation on the Lists of Addictive Substances do not specify the criteria for substance scheduling either. Consequently, in order to open discussion on the relevancy of the present classification of narcotic and 
psychotropic substances, we need to work with other documents that provide some commentary and elucidate the grounds for such classification. One such document could be, for example, "Amphetamine-Type Stimulants - A Global Review" (http://www.unodc.org/pdf/technical_series_199601-01_1.pdf), prepared by UNDCP at the request of the Commission on Narcotic Drugs, under which substances are classified according to their risk to public health and their medicinal use. Schedule 1 includes substances with high public health risk and questionable or no therapeutic utility, while the public health risk becomes progressively lower and therapeutic utility progressively higher in Schedules 2, 3 , and 4 .

A much more clearly arranged document when it comes to substance classification is the US Controlled Substances Act (http://www.fda.gov/regulatoryinformation/ legislation/ucm148726.htm). According to its provisions, substances are classified as Schedule 1 under the following criteria:

- the drug or other substance has a high potential for abuse,

- the drug or other substance has no currently accepted medical use in treatment in the United States,

- there is a lack of accepted safety for use of the drug or other substance under medical supervision (http:// www.fda.gov/regulatoryinformation/legislation/ucm 148726.htm).

Addiction potential, extent of therapeutic use, and safety of psychedelic substances have all been the subject of a heated discussion among professionals as well as the general public. The following passage will provide a summary of the current state of knowledge on these three aspects with a specific focus on psilocybin, one of the active substances of the psychoactive Psilocybe mushrooms.

\section{Psychedelics and addiction}

The interpretation of various terms appearing in the wording of Czech, international, and US legislation may be more intricate than it seems. The commonly used terms "abuse," "use," "misuse," and "dependence," or "addiction" are easily misinterpreted. When explaining the classification of controlled substances, the international conventions and their Czech translations refer to the substances' capacity to produce a "state of dependence" or about their "abuse." The US Controlled Substances Act only mentions that the substance has a potential for abuse.

According to one of the sources cited on the WHO webpage (http://www.who.int/topics/substance_abuse/en/), substance abuse refers to harmful or hazardous use of psychoactive substances and pertains to legal as well as illegal substances, also referring to the fact that psychoactive substances can produce addiction. Addiction is a phenomenon affecting behavioral, cognitive, and psychological aspects of an individual's personality; a syndrome that consists of a number of clearly defined symptoms; a disorder clearly recognized by International Classification of Diseases (ICD-10), which can emerge as a result of repeated use of certain substances. In its interpretation of the term, WHO also proposes a comparison with DSM-IV, the
American Psychiatric Association's system for the classification of mental disorders, according to which "substance abuse" refers to continued use despite awareness of persisting social, occupational, psychological, and physical difficulties associated with the use of the substance. Another example of substance abuse is the use of prescribed controlled substances in excess of the recommended doses. However, the term is often used inaccurately - only based on the fact that the given substance is included in the list of controlled substances, regardless of the pattern of use or its health impacts (http://www.who.int/substance_abuse/ terminology/abuse/en/).

According to a WHO definition, hazardous use (http:// www.who.int/substance_abuse/terminology/definition3/en/) denotes a pattern of psychoactive substance use that increases the risk of harmful consequences for the user. On the contrary, harmful use (http://www.who.int/substance abuse/terminology/definition2/en/) is a pattern of psychoactive substance use that causes damage to the user's physical and psychological health. Since practically all substances, including sugar, water, and oxygen, can be considered hazardous or harmful under certain circumstances, this definition should not be central to the assessment of the safety of a substance, especially if we consider the frequency of hazardous and harmful usage patterns of legal substances or substances classified in other categories (alcohol, nicotine, benzodiazepines, and inhalants). The criteria for substance classification according to the Convention on Psychotropic Substances only include the capacity to produce dependence, public health issues, and social issues. Due to a marked ambiguity in the meaning and possible interpretations of the term "abuse," we will now focus specifically on the addiction potential of classical psychedelics.

The ICD-10 defines dependence as a cluster of behavioral, cognitive, and physiological phenomena that develops after repeated substance use and typically includes strong desire to take the psychoactive drug (craving), impaired control over its use, continued use despite harmful consequences, higher priority of drug use over other activities and commitments, increased drug tolerance, and sometimes physical withdrawal (http://www.uzis.cz/cz/mkn/ index.html). Therefore, it can be considered as a cluster of symptoms, which includes physical as well as psychological symptoms and is common to legal and illegal substances, regardless of classification. Divisions, such as "hard and soft" drugs or considerations of whether a particular substance causes physical or psychological dependence, are not key for the treatment of this disorder. Dependence is not a disease caused merely by the effect of an exogenous substance on the organism (unlike acute intoxication), but a multifactorial disorder determined by biological, psychological, social, and spiritual factors.

\section{Bio-psycho-social-spiritual (BPSS) model of addiction}

Biological factors include congenital dispositions, impact of the mother's use on the fetus or the child shortly after birth, or the capacity of certain substances to have long-term impact on the reward system. The reward system is key to the individual's survival, its task being to recognize 
biologically significant stimuli and to elicit behavioral response. Since the principal function of this system is to preserve the individual and the species, natural stimuli that activate the reward system include mainly food, water, and sex. Activation of the reward system is caused by an increase in the extracellular concentration of dopamine in the nucleus accumbens. In this way, the individual learns that the given stimulus provides reward in connection with a positive affective response and starts to be required in order to produce this response. The development of addiction and the emergence of uncontrollable craving are associated with a direct disturbance of the dopaminergic "reward" pathways in the limbic system (the mesolimbic pathway) and indirectly it also damages emotional and cognitive limbic circuits (Okruhlicová, 2012). Substances that have a direct effect on the mesolimbic dopaminergic pathway are thus considered to have a high addiction potential, e.g., opiates, nicotine, phencyclidine, cocaine, amphetamine, alcohol, benzodiazepines, barbiturates, or caffeine (Nichols, 2004).

Psychological factors affecting the development and continuation of addiction include mainly disorders of psychological development, possibly caused by insufficient prenatal and postnatal care, unsatisfactory responses to the child's development and to the differentiation of its needs or inadequate saturation of these needs within certain limits; support in adolescence during the development of identity, and adequate assistance in the event of emergence of various psychiatric disorders such as depression, anxiety, or psychosis. One of the theories that support the pivotal role of psychological factors in the development and perpetuation of addiction is the self-medication theory: the pharmacological effect of the substance alleviates the user's psychological difficulties and is conducive to long-term substance consumption (Kudrle, 2003).

Social factors affecting the development of addiction include family-related factors, social environment including the influence of society as a whole at the level of drug policy of the given country, and the acceptability of substance use in that country or culture. Finally, the spiritual aspect comprises the impact of faith and spiritual values on substance use or on the search for a spiritual framework. The factors that affect the development and continuation of addiction can be divided into risk factors and protective factors. An interesting breakthrough in the study of addiction potential in animal studies was a controversial article by Alexander, Beyerstein, Hadaway, and Coambs (1981), which focused on the impact of society and the fulfillment of social needs on the development and perpetuation of morphine addiction in rats. Until that time, during most studies, rats were placed in cages alone, with the possibility of choosing between drinking plain water or water containing morphine. However, Alexander created a space called the "Rat Park," in which there was a whole group of rats of both sexes with a multitude of possibilities such as mating or playing with a large number of toys and devices including running wheels and balloons. This experiment revealed that the addiction potential of the chemical is not sufficient to produce addiction. Rats locked up in isolation without social contact preferred morphine-laced water to plain water, whereas rats living in the company of others preferred plain water with occasional use of doses of morphine low enough so as not to disrupt their social role. This experiment supports the hypothesis that social isolation has a significant impact on the development and perpetuation of addiction.

\section{Classical psychedelics from the perspective of the BPSS model}

The biological mechanism of action of classical psychedelics is agonism at serotonin 2A receptors (5-HT2A). Even though some psychedelics also have affinity for dopaminergic receptors (e.g., LSD; Ray, 2010) or have a secondary effect on the dopaminergic system via serotonergic mechanisms (Vollenweider, Vontobel, Hell, \& Leenders, 1999), they do not activate the reward center associated with addictive behavior (nucleus accumbens).

It could be stated that psychedelics act on the serotonergic system, similar to modern antidepressants, but their mechanism of action is probably very different at the receptor level. Another mechanism of antidepressant action that is probably common to psychedelics and antidepressants is neuroplasticity (Tylš, 2017). The stimulation of synaptogenesis allows for greater flexibility, promotes learning, and can therefore be a significant supporting factor during addiction recovery. In contrast with the necessity of long-term use in the case of antidepressants, psychedelics appear to be able to elicit their proneuroplastic effect after a single dose (Carhart-Harris et al., 2016). Antidepressants decrease limbic response and inhibit emotional activity, effectively limiting negative but also positive emotional processing. Classical psychedelics, on the other hand, work as emotional catalysts, facilitating the initiation of processes that (often in combination with psychotherapy) may lead to a catharsis of suppressed feelings and emotions. This may have a substantial impact on the individual's psychological health and consequently also on the development and perpetuation of addictive behaviors. Classical psychedelics have been proven to have a beneficial effect in the therapy of addiction to alcohol (Bogenschutz et al., 2015), tobacco (Johnson et al., 2014), opiates, and other substances (Brown, 2013; Thomas, Lucas, Capler, Tupper, \& Martin, 2013).

Qualitative studies and population studies demonstrate that the use of psychedelics in a predominantly recreational context is associated with a decreased incidence of mental health problems (Bouso et al., 2012; Carhart-Harris \& Nutt, 2010, 2013; Hendricks, Thorne, Clark, Coombs, \& Johnson, 2015; van Amsterdam, Nutt, Phillips, \& van den Brink, 2015). Recreational use was actually associated with deepening of interpersonal relationships, positive attitude toward one's self and one's body, and with acceptance of suppressed emotions (Watts, Krzanowski, Nutt, \& CarhartHarris, 2017). Interpersonal problems, low self-confidence, and negative self-image are marked risk factors for the development of addiction (Offord \& Bennett, 2002), and psychedelics use therefore appears to be a protective factor in this respect.

Long-term use of psychedelics does not cause craving or physical withdrawal. Due to a rapid onset of tolerance (or tachyphylaxis), caused by 5-HT2A receptor downregulation (Roth et al., 1995), the effects of psychedelics decrease rapidly with repeated use, and this is why there is no 
evidence of impaired behavioral control in the use of psychedelics in terms of frequency or dosing (Canal \& Murnane, 2017). Other symptoms of addiction according to ICD-10 such as progressive neglect of alternative interests and pleasures are not present with psychedelics actually, we typically encounter quite the opposite - for example, Watts describes restarting previous hobbies in several cases of treatment resistant depressive patients treated with psilocybin (Watts et al., 2017). The last criterion is persistent substance use despite harmful consequences. Nichols (2016) points out that the classical psychedelics produce psychedelic effects and altered states of consciousness in doses that are very far from being toxic to human organs. Furthermore, their effect on the autonomic nervous system is very mild (only minor sympathomimetic effect). The harms of psychedelics will be discussed in more detail in Chapter 3C.

For the diagnosis of "dependence syndrome," at least three of the aforementioned symptoms (highlighted in italicized) must be present during the past year. With classical psychedelics, it is practically impossible to diagnose dependence syndrome, as they are not associated with the vast majority of these symptoms (with the exception of rapid tolerance; however, the tolerance observed in substances with high addiction potential is of a different nature, building up gradually with repeated use). If we encounter dependence syndrome in users of classical psychedelics in clinical practice, it typically co-occurs with the consumption of other narcotic or psychotropic substances. If we look at the data from the Annual Report on Drug Situation in the Czech Republic (Mravćík et al., 2016), issued every year by the National Monitoring Centre for Drugs and Drug Addiction, we can see that of the whole population of the Czech Republic, which was 10.5 million people as of 2015 (https:/www.czso.cz/csu/czso/cri/pohyb-obyvatelstva4-ctvrtleti-2015), 4\% have used LSD and 7.3\% some type of psychedelic mushrooms (there are no available data for other psychedelics.). In 2015, zero mushroom users and only three LSD users were reported to ask for help in any facility for addiction treatment (with none of them being first-time clients, that is, all of them previously asked for help in connection with drug addiction) - out of the total of 7,641 applicants for addiction treatment in that year. This further supports the claim that addiction-related issues are something we normally do not encounter among psychedelic users.

\section{Use of psychedelics in contemporary medicine}

In the 1960s, a number of clinical studies were conducted using LSD or synthetic psilocybin. Both compounds were manufactured and distributed by the Swiss pharmaceutical company Sandoz under the names Delysid and Indocybin, respectively. LSD was also manufactured by Czechoslovak company Spofa in a preparation named Lysergamid (Stafford, 1997). Psychedelics were considered to be essential tools for understanding the etiopathogenesis of certain mental health disorders and were assumed to have a therapeutic potential. Even though, from the contemporary perspective, these studies can be challenged in terms of methodology, until the end of the 1960s, thousands of scientific papers were published describing the beneficial effects of the administration of psychedelics by more than 40 thousand patients in various indications with minimal adverse effects and a good safety profile (Grinspoon \& Bakalar, 1981; Masters \& Houston, 1970). The use of psychedelics in medicine was practically impossible for several decades due to strict regulations. However, despite the fact that the legal framework has not seen any changes since then, the research of the therapeutic potential of psychedelics has recently made a return to the limelight (Sessa, 2005; Vollenweider \& Kometer, 2010).

The beneficial effects of psychedelics as anxiolytics and antidepressants in patients with terminal-stage cancer without clinically significant adverse effects have been proven in several studies (Griffiths et al., 2016; Grob et al., 2011). Psychedelic therapy supports the patients' ability to come to terms with their condition, helps them accept what it means for their lives, and decreases their fear of death. Secondary to this, patients also report to experience pain relief (Gasser, Kirchner, \& Passie, 2015; Griffiths, 2007; Kumar, 2009; Richards, Grof, \& Goodman, 1972; Ross, 2009).

Case reports and clinical trials have also shown a potential in the treatment of OCD (Brandrup \& Vanggaard, 1977). In one patient, symptom relief persisted for a period of 5 months following a single dose (Leonard \& Rapoport, 1987; Moreno, Wiegand, Taitano, \& Delgado, 2006). Psychedelic therapy also appears to be beneficial in the treatment of alcoholism (Bogenschutz et al., 2015; Smart \& Storm, 1964) and tobacco addiction (Johnson \& Cosimano, 2012). The assumption is that psychedelics amplify the capability for introspection and self-reflection and they boost the individual's motivation to overcome addiction. Furthermore, certain psychedelics (LSD and psilocybin) have been proven to have benefit in the treatment of cluster headaches (a type of severe and recurrent headaches), effectively decreasing the intensity of an attack and prolonging the intervals in between attacks after a single administration (Sempere, Berenguer-Ruiz, \& Almazan, 2006; Sewell, Halpern, \& Pope, 2006).

Recently, psychedelics have shown most promise in the treatment of depression including its treatment-resistant forms (Baumeister, Barnes, Giaroli, \& Tracy, 2014; Carhart-Harris et al., 2016; Vollenweider \& Kometer, 2010). In a recent study conducted by Carhart-Harris et al., all patients in the sample experienced significant decrease in symptom intensity or even complete remission following the administration of a single high dose of psilocybin (preceded by a low dose 1 week earlier). According to standard evaluation criteria, 1 week after the second dose, $8(67 \%)$ out of 12 patients achieved complete remission, and 3 months after the session, 7 patients (58\%) still met the criteria for treatment response, out of which $5(42 \%)$ were still in complete remission. The patients also experienced a significant decrease in anxiety (STAI-T scale) and anhedonia (Snaith-Hamilton Pleasure Scale) scores compared to their previous scores (Carhart-Harris et al., 2016).

Studies conducted with healthy volunteers in controlled environment have demonstrated long-term positive changes in personal life associated with the psychedelic experience. Most of the subjects reported that it was among the most 
significant experiences of their lives. Also reported were positive changes in the subjects' outlook on the world and subjective values, their perception of personal issues, own body, other people and the environment, and changes in the aesthetic perception of and attitude toward altered states of consciousness (Carhart-Harris \& Nutt, 2013; Doblin, 1991; Griffiths et al., 2012; Griffiths, Richards, McCann, \& Jesse, 2006; Majic, Schmidt, \& Gallinat, 2015; Winkler \& Csémy, 2014). A number of recent studies suggest that psychedelicassisted psychotherapy may be effective in the treatment of personality disorders (Maclean, Johnson, \& Griffiths, 2011; Pokorný, 2016; Watts et al., 2017).

The currently available pharmacological treatment of addiction, anxiety, and affective disorders has limited efficacy and often causes significant side effects that may, among other things, interfere with the patient's willingness to adhere to the prescribed regimen. None of the cited studies have reported any serious adverse effects associated with the use of psychedelics, further supporting the safety of their clinical use. The results available to date clearly indicate that certain patients could benefit from psychedelics as a fast-acting treatment option with long-term effect and minimal adverse effects (Santos et al., 2016).

\section{RISKS ASSOCIATED WITH PSYCHEDELIC USE IN MEDICAL AND RECREATIONAL CONTEXTS}

The use of psychedelics - whether in a recreational, scientific or therapeutic context - requires a conscientious approach in order to provide adequate set and setting ("Set" refers to the mindset of an individual - their mood, expectations, and intention. "Setting" represents external conditions of such as the location or the people the user is surrounded by). The essentials of contemporary human studies with psychedelics include providing sufficient information about the substance and its effects, making sure the participant makes the decision to use the substance of their own volition, ensuring a safe and comfortable environment, and providing a reliable and experienced guide/therapist. Specific recommendations for providing a safe environment and guidelines for research and therapy can be found, for example, in the Handbook for the Therapeutic Use of Lysergic Acid (Blewett \& Chwelos, 1959), LSD Psychotherapy (Grof, 1980), or in a review article by Johnson, Richards, and Griffiths (2008). In the Czech context, we can also utilize the experience gained in an ongoing clinical trial with psilocybin, conducted in a specially designed room in the Czech National Institute of Mental Health (Bravermanová et al., 2018; Tylš et al., 2016).

Classical hallucinogens in general have a very low toxicity in the human body, and they have not been shown to cause organ toxicity or neurological damage (Gable, 1993, 2004; Halpern \& Pope, 1999; Halpern, Sherwood, Hudson, Yurgelun-Todd, \& Pope, 2005; Hasler, Grimberg, Benz, Huber, \& Vollenweider, 2004; Nichols, 2004; Strassman, 1984). Unlike other drugs of abuse, psilocybin and LSD have a wide therapeutic window, that is, a broad range between the effective dose and the lethal dose, and they have a very low addiction potential (Fish, 2006).
High doses of these compounds can cause unpleasant physical reactions associated with their mild sympathomimetic effect: dizziness, tremor, nausea, drowsiness, changes in perception such as tingling, stinging, itching or burning sensation in the skin, blurred vision, pupil dilation, increased deep tendon reflexes, and mild elevation of heart rate and systolic and diastolic blood pressure. These physical symptoms vary among individuals, are relatively insignificant even in doses that elicit profound psychological effect (Johnson et al., 2008), and subside together with the drug's acute effect.

In a research conducted by the Independent Council on Drug Harms, a panel of scientists were asked to assess the harms caused by drugs to the individual as well as his or her environment based on 16 criteria. Of the 20 evaluated substances, psilocybin and LSD ended up last of all (no other classical psychedelics were included), while alcohol ranked first and nicotine sixth (Nutt, King, \& Philips, 2010; van Amsterdam et al., 2015). A statistical analysis of the evaluation of harms caused by legal and illegal narcotic and psychotropic substances by 292 Scottish clinicians indicates that there is a notable imbalance in the present international system for drug classification. The results were incongruous with the present scheduling and with substance legality: e.g. heroin as a Schedule 1 substance ranked first (i.e., experts consider it the most harmful), while THC (a Schedule 1 substance as well) was evaluated as the least harmful of all 19 most frequently used drugs. According to the experts, legal drugs not listed among the narcotic and psychotropic substances such as alcohol, nicotine, and organic solvents are considerably more harmful than certain Schedule 1 substances such as LSD or psilocybin. Certain substances classified as Schedule 3 (i.e., the least controlled group), such as benzodiazepines, barbiturates, or some amphetamines, have also scored higher than classical psychedelics (Taylor et al., 2012).

Studerus, Kometer, and Hasler (2011) studied the acute, subacute, and persisting long-term subjective effects of psilocybin in a group of 110 volunteers, and the findings show that only the limited number of the participants perceived the experience as negative (specifically those receiving the two highest doses in the study with the highest dosage being $315 \mu \mathrm{g} / \mathrm{kg}$ ). They described the experience as involving strong dysphoria, anxiety, and panic. In all cases, such acute reactions were successfully managed by interpersonal support without the need for pharmacological intervention. In the long-term, the volunteers did not show any other problems such as drug abuse, persisting changes in perception, psychosis, or problems in everyday life. On the contrary, most of them rated the experience as pleasant, enriching, and generally not endangering.

Recent studies have shown that psychedelics are relatively safe even when used without medical supervision, although it is clear that recreational use without the safety of a controlled environment may certainly be more challenging. In their nationwide population study, Krebs and Johansen (2012, 2013; Johansen \& Krebs, 2015) found no link between increased risk of mental health disorders and the use of psychedelics (LSD, psilocybin, and mescaline specifically). According to a study on 190,000 respondents 
carried out in the USA by Hendricks et al. (2015), lifetime classical psychedelic use was associated with a significantly reduced occurrence of psychological distress, suicidal thinking, suicidal planning, or suicide attempts.

The acute effects of psychedelics bear striking resemblance to psychosis. However, despite the partial phenomenological validity of the so-called serotonergic model of psychosis, reports of psychedelics triggering acute psychosis are actually very rare (Tylš, 2016). With that said, even though classical psychedelic use does not appear to increase the incidence of mental health disorders, it is not impossible that it may have an effect on the development of schizophrenia. This is why positive personal or family history of psychosis or psychotic symptoms secondary to a primary diagnosis (e.g., depression with psychotic symptoms) is a standard exclusion criterion in all studies with psychedelic substances (Bravermanová et al., 2018). Even though there is no conclusive proof to date, psychedelics are considered a potential non-specific trigger of this serious disorder, similar to other psychotropics (the risk is considerably higher in cannabis and amphetamines) or highly stressful life events. It is, nevertheless, important to emphasize that psychedelics are not a specific etiological agent in schizophrenia (Tylš, 2016).

Halpern et al. (2005) examined the cognitive function and neuropsychological changes in 61 members of the Navajo Native American Church (Navajo Native American Church is a Native American religion that combines the elements of Christianity and traditional Native American faiths. It involves sacramental use of peyote as a means of communication with the Great Spirit, a supernatural entity resembling the Christian God.) who regularly used peyote [it (Lophophora williamsii) is a psychoactive cactus species containing the hallucinogenic alkaloid mescaline. It is native to North America, mainly distributed in Mexico.] (150-500 uses per lifetime), and found no significant changes in comparison with the control sample. Regular peyote users even exhibited signs of better mental health. In another study with 22 regular ayahuasca consumers (at least 50 uses in the past 2 years), Bouso et al. (2012) discovered no deficit in neuropsychological performance.

\section{PROPOSED SOLUTION FOR THE CURRENT SITUATION IN THE CZECH REPUBLIC AND THE WORLD}

The question remains: How is it possible that psychedelics substances that have been used by humans for millennia, be it as medicines or tools for spiritual enlightenment - are not available in the Western society?

Tomáš Páleníček, head of psychedelic research in the Czech National Institute of Mental Health, claims that one of the main obstacles is the current classification of psychedelics among substances without therapeutic utility (personal correspondence). It would therefore be advisable to take the steps necessary in order to reclassify these substances into another schedule (with medicinal use). This process should start at the level of scientific research, but it also needs to incorporate the education of the general public, while both levels should use correct and consistent terminology and adhere to a common procedure in order to facilitate such changes in the future as effectively as possible.

If we choose a particular psychedelic substance as a prospective medicinal product, we can align research interests with the application for marketing authorization of a new medicinal product. One option is to conduct a clinical trial of a non-authorized medicinal product pursuant to Section 51-59 of Act no. 378/2007 Coll. on pharmaceuticals and on amendments to some related acts ("Act on Pharmaceuticals"). Such clinical trials are subject to approval by the Czech State Institute for Drug Control ("SÚKL") and an ethics committee appointed by the healthcare provider or the Ministry of Health.

Clinical trials of non-authorized medicinal products, preclinical trials, and pharmaceutical safety trials (Section 26 of Act no. 378/2007 Coll.) are a prerequisite for obtaining a marketing authorization for any new medicinal product in the Czech Republic.

In order to perform these trials, a certified supplier of the investigational product is needed as well; moreover, for Schedule 4 substances, both the research team and the supplier need a handling permit. Upon successful completion of the clinical trial, it is possible to file an application for marketing authorization of the medicinal product in a specific pharmaceutical formulation pursuant to Act no. 228/2008 Coll. on the marketing authorization of medicinal products, which defines the steps and documents required for such an application. Successfully completed authorizations can also be processed by way of the mutual recognition procedure from other member countries of the EU in accordance with Section 44 of the Act on Pharmaceuticals.

If the psychedelic substance succeeds in obtaining marketing authorization pursuant to Section 39 of the Act on Pharmaceuticals, which introduces the classification of human medicinal products for the dispensing and sale of designated pharmaceuticals, the Ministry of Health determines whether the medicinal product will be available by prescription only, by restricted prescription only, or without prescription ("over the counter"). This would require reclassification of the given substance into a schedule of substances available by prescription, as currently no Schedule 4 drug can be made available by prescription or sold over the counter in pharmacies. Relevant indications such as treatment-resistant depression (in this particular case it is, moreover, necessary to further specify the diagnostic criteria for this condition), OCD, anxiety associated with terminal illness, addiction, and others - should be specified in the application for marketing authorization as well.

Another necessary step is to create a list of medical professions authorized to handle such medicinal products. The authors are of the opinion that the requirements should include expertise in clinical psychiatry as well as in psychotherapy due to the specifics of psychedelic treatment. These areas of expertise could be provided by multiple persons within one team. The presence of a clinical psychiatrist appears to be beneficial mainly due to the necessity of evaluating potential risks during the screening phase, but also in order to allow for pharmacological intervention in the 
event of serious adverse effects (e.g., administering an antihypertensive or an anxiolytic). Psychedelics should be available by restricted prescription only and prescription should be limited to certified psychiatrists. The presence of an experienced psychotherapist is essential and the requirements should include a completed certified psychotherapy training of a non-directive, dynamic modality, and a specialized follow-up certification in psychedelic-assisted psychotherapy, accredited by the Ministry of Health. There is no such certification in the Czech Republic to date, but any future efforts could draw inspiration from the program of Psychedelic-assisted Therapy and Research at the California Institute of Integral Studies, which has been started in 2016 and is currently the only one of its kind in the world. The Swiss Medical Society for Psycholytic Therapy is currently preparing a similar training.

Another important issue is to secure the supply of these substances, logistically as well as economically, that is, to find or establish a laboratory with the capacity to produce psilocybin for human use in accordance with applicable law, to arrange for appropriate distribution and availability in pharmacies, decide on an adequate price for the medicinal product, and possibly negotiate potential coverage with health insurance companies.

At this point, more preclinical and pharmaceutical trials of psilocybin are still needed. Furthermore, certain documents required for the application for marketing authorization of psilocybin as a medicinal product need to be drafted and submitted to SÚKL (the requirements are listed in Section 26 of the Act on Pharmaceuticals or on SÚKL's website). One clinical trial with psilocybin is already underway at the Czech National Institute of Mental Health, led by Dr Páleníček and his team.

In the context of the Czech drug legislation, there is one more option apart from the rescheduling of psilocybin: to create a subunit of medicinal psilocybin, similar to the current legal status of medicinal cannabis. In this case, marijuana remained in List no. 3, but a new subunit named "cannabis for therapeutic use" was created and scheduled as List no. 1, making it available for medical use. The example of cannabis and its reclassification (or, in some countries, even complete legalization for recreational purposes) shows that the fact that a substance is classified as Schedule 1 equivalent to the Czech List no. 4 and also List no. 3 in the case of cannabis - does not preclude it from being used in therapy as long as the particular country takes the necessary steps to amend its legal framework. Fear of violating international conventions is unfounded and results from social pressure, political disinformation, and lack of knowledge about the applicable Czech as well as international law. Unfortunately, the newly established Workgroup for the Medicinal Use of Psychoactive Substances and Plants, part of the Government Council for Drug Policy Coordination, has not yet started to engage itself with the issue of rescheduling psilocybin and other classical psychedelics.

\section{CONCLUSIONS}

Classical psychedelics have a broad spectrum of potential therapeutic utility, their use does not lead to the development of addiction, and their administration under medical supervision is safe. All of these evidence-based claims are incongruous with the UN classification system. Moreover, there is no evidence linking psychedelics with an increased risk of health-related or social problems. In fact, the opposite seems to be the case: psychedelics are associated with lower incidence of mental health disorders and are known to have been used by indigenous cultures as traditional medicine for centuries. The western medical model has rigorous methods for testing "new" medicines, and in order to introduce these substances into the Czech medical system, we need to adhere to the rules set out by the Ministry of Health and go through the standard process of obtaining marketing authorization for these substances as medicinal products.

The main obstacle in the way of the necessary rescheduling of certain psychedelic substances is the general ignorance or indifference of the policymakers, researchers, and society in general - in relation to both the legal framework as well as evidence-based facts about psychedelics. An analysis of legal documents relevant to the Czech context reveals that rescheduling of certain psychedelic substances, currently included in List no. 4 of the Government Regulation no. 463/2013 Coll. on the lists of addictive substances, to the list of substances that are available by restricted prescription is a viable option, guaranteed by the Czech Charter of Fundamental Rights and Freedoms, the Code of Ethics of the Czech Medical Chamber, the UN Convention on Psychotropic Substances, and Act on Addictive Substances.

The marketing authorization for psychedelics as medicinal products and their rescheduling is, however, contingent on the cooperation of many institutions (Ministry of Health, State Institute for Drug Control, Government Council for Drug Policy Coordination, researchers and physicians, psychotherapists, pharmaceutical manufacturers, and others). The scientific as well as administrative staff involved in psychedelic research is required to respect the evidencebased approach, which is one of the main principles of the drug policy of the Czech Republic. The requirement for scientific research is clearly specified in a document named "The National Drug Policy Strategy for the Period 2010 to 2018," adopted by virtue of Government Resolution no. 340 on May 10, 2010, amended by Government Resolution no. 54 on January 25, 2016, which is modeled on the WHO policy of "Health for All in the 21st Century." The National Drug Policy Strategy stipulates that "realistic drug policy and its execution is grounded in the results of analyses of the present situation and reflects the identified problems, needs and priorities. In other words, it is based on scientifically verified facts and data, not on assumptions and speculation. Scientific research and the translation of its findings into practice should be supported in the interest of introducing and employing proven and effective strategies and interventions" (https://www.vlada.cz/assets/ppov/protidrogovapolitika/strategie-a-plany/NSPP_revize_II.pdf).

Acknowledgements: The authors received no financial support for writing this article. The credit for assistance with its preparation belong to MUDr. Tomáš Páleníček, $\mathrm{PhD}$ who helped clarify key information about the ongoing 
psychedelic research in the Czech Republic and reviewed the article. The original Czech version of the article was edited and translated into English by Bc. Jan Tichý. The correctness of the legal provisions was checked by Mgr. Michal Kyjonka.

Conflict of interest: The authors report no conflict of interest. They alone are responsible for the content and writing of this article.

\section{REFERENCES}

Alexander, B., Beyerstein, B., Hadaway, P., \& Coambs, R. (1981). Effect of early and later colony housing on oral ingestion of morphine in rats. Pharmacology Biochemistry and Behavior, 15(4), 571-576. doi:10.1016/0091-3057(81)90211-2

Austin, J., \& McVey, A. (1989). Focus (newsletter). The impact of the war on drugs. San Francisco, CA: National Council on Crime and Deliquency.

Baumeister, D., Barnes, G., Giaroli, G., \& Tracy, D. (2014). Classical hallucinogens as antidepressants? A review of pharmacodynamics and putative clinical roles. Therapeutic Advances in Psychopharmacology, 4(4), 156-169. doi:10.1177/204512 5314527985

Blewett, D., \& Chwelos, N. (1959). Handbook for the therapeutic use of lysergic acid diethylamide 25 individual and group procedures. Retrieved February 16, 2017, from https://www. erowid.org/psychoactives/guides/handbook_1sd25.shtml

Blocker, J. (2006). Did prohibition really work: Alcohol prohibition as a public health innovation. American Journal of Public Health, 96(2), 233-243. doi:10.2105/AJPH.2005.065409

Bogenschutz, M. P., Forcehimes, A. A., Pommy, J. A., Wilcox, C. E., Barbosa, P. C., \& Strassman, R. J. (2015). Psilocybinassisted treatment for alcohol dependence: A proof-of-concept study. Journal of Psychopharmacology, 29(3), 289-299. doi:10.1177/0269881114565144

Bouso, J., González, D., Fondevila, S., Cutchet, M., Fernández, X., Ribeiro Barbosa, P. C., Alcázar-Córcoles, M. Á., Araújo, W. S., Barbanoj, M. J., Fábregas, J. M., \& Riba, J. (2012). Personality, psychopathology, life attitudes and neuropsychological performance among ritual users of ayahuasca: A longitudinal study. PLoS One, 7(8), e42421. doi:10.1371/ journal.pone. 0042421

Brandrup, E., \& Vanggaard, T. (1977). LSD treatment in a severe case of compulsive neurosis. Acta Psychiatrica Scandinavica, 55(2), 127-141. doi:10.1111/j.1600-0447.1977.tb00149.x

Bravermanová, A., Viktorinová, M., Tylš, F., Novák, T., Androvicová, R., Korcák, J., Horáček, J., Balíková, M., Griškova-Bulanova, I., Danielová, D., Vlček, P., Mohr, P., Brunovský, M., Koudelka, V., \& Páleníček, T. (2018). Psilocybin disrupts sensory and higher order cognitive processing Study on P300 and mismatch negativity in healthy volunteers. Psychopharmacology, 235(2), 491-503. doi:10.1007/s00213017-4807-2

Brown, T. (2013). Ibogaine in the treatment of substance dependence. Current Drug Abuse Reviews, 6(1), 3-16. doi:10.2174/ 15672050113109990001

Canal, C., \& Murnane, K. (2017). The serotonin 5-HT2C receptor and the non-addictive nature of classic hallucinogens. Journal of Psychopharmacology, 31(1), 127-143. doi:10.1177/0269 881116677104

Carhart-Harris, R. L., \& Nutt, D. J. (2010). User perceptions of the benefits and harms of hallucinogenic drug use: A web-based questionnaire study. Journal of Substance Use, 15(4), 283-300. doi:10.3109/14659890903271624

Carhart-Harris, R. L., \& Nutt, D. J. (2013). Experienced drug users assess the relative harms and benefits of drugs: A web-based survey. Journal of Psychoactive Drugs, 45(4), 322-328. doi:10.1080/02791072.2013.825034

Carhart-Harris, R. L., Bolstridge, M., Rucker, J., Day, C. M., Erritzoe, D., Kaelen, M., Bloomfield, M., Rickard, J. A., Forbes, B., Feilding, A., Taylor, D., Pilling, S., Curran, V. H., \& Nutt, D. J. (2016). Psilocybin with psychological support for treatment-resistant depression: An open-label feasibility study. The Lancet Psychiatry, 3(7), 619-627. doi:10.1016/S2215-0366(16)30065-7

Crockford, R. (2007). LSD in Prague: A long-term followup study. MAPS Bulletin, XVII(1), 20-22. Retrieved from http://www.maps.org/news-letters/v17n1/1sd_in_prague-long_ term_followup_study.pdf

Doblin, R. (1991). Pahnke's good friday experiment a long-term follow-up and methodological critique. The Journal of Transpersonal Psychology, 23(1), 1-28.

Fischer, F. (2015). Therapy with substance: Psycholytic psychotherapy in the twenty first century. London, UK: Muswell Hill Press.

Fish, J. M. (2006). Drugs and society: US public policy. Lanham, MD: Rowman \& Littlefield.

Gable, R. (1993). Toward a comparative overview of dependence potential and acute toxicity of psychoactive substances used nonmedically. The American Journal of Drug and Alcohol Abuse, 19(3), 263-281. doi:10.3109/00952999 309001618

Gable, R. (2004). Comparison of acute lethal toxicity of commonly abused psychoactive substances. Addiction, 99(6), 686-696. doi:10.1111/j.1360-0443.2004.00744.x

Gasser, P., Kirchner, K., \& Passie, T. (2015). LSD-assisted psychotherapy for anxiety associated with a life-threatening disease: A qualitative study of acute and sustained subjective effects. Journal of Psychopharmacology, 29(1), 57-68. doi:10.1177/0269881114555249

Geyer, M., \& Vollenweider, F. (2008). Serotonin research: Contributions to understanding psychoses. Trends in Pharmacological Sciences, 29(9), 445-453. doi:10.1016/j.tips.2008. 06.006

Griffiths, R. (2007). Psychopharmacology of psilocybin in cancer patients (ClinicalTrials.gov Identifier NCT00465595). Sidney Kimmel Comprehensive Cancer Center, ClinicalTrials.gov (online). Retrieved from http://www.clinicaltrials.gov/ct2/ show/study/NCT00465595?term=Psilocybin

Griffiths, R. R., Johnson, M. W., Carducci, M. A., Umbricht, A., Richards, W. A., Richards, B. D., Cosimano, M. P., \& Klinedinst, M. A. (2016). Psilocybin produces substantial and sustained decreases in depression and anxiety in patients with life-threatening cancer: A randomized double-blind trial. Journal of Psychopharmacology, 30(12), 1181-1197. doi:10.1177/0269881116675513

Griffiths, R. R., Johnson, M. W., Richards, W. A., Richards, B. D., McCann, U., \& Jesse, R. (2012). Psilocybin occasioned mysticaltype experiences: Immediate and persisting dose-related effect. 
Psychopharmacology, 218(4), 649-665. doi:10.1007/s00213011-2358-5

Griffiths, R. R., Richards, W. A., McCann, U., \& Jesse, R. (2006). Psilocybin can occasion mystical-type experiences having substantial and sustained personal meaning and spiritual significance. Psychopharmacology, 187(3), 268-283. doi:10.1007/ s00213-006-0457-5

Grinspoon, L., \& Bakalar, J. B. (1981). The psychedelic drug therapies. Current Psychiatric Therapies, 20, 275-283.

Grob, C., Danforth, A., Chopra, G., Hagerty, M., McKay, C. R., Halberstadt, A. L., \& Greer, G. R. (2011). Pilot study of psilocybin treatment for anxiety in patients with advancedstage cancer. Archives of General Psychiatry, 68(1), 71-78. doi:10.1001/archgenpsychiatry.2010.116

Grof, S. (1980). LSD psychotherapy. Pomona, CA: Hunter House.

Halpern, J., \& Pope, H. (1999). Do hallucinogens cause residual neuro-psychological toxicity. Drug and Alcohol Dependence, 53(3), 247-256. doi:10.1016/S0376-8716(98)00129-X

Halpern, J., Sherwood, A., Hudson, J., Yurgelun-Todd, D., \& Pope, H. (2005). Psychological and cognitive effects of longterm peyote use among Native Americans. Biological Psychiatry, 58(8), 624-631. doi:10.1016/j.biopsych.2005.06.038

Hasler, F., Grimberg, U., Benz, M., Huber, T., \& Vollenweider, F. (2004). Acute psychological and physiological effects of psilocybin in healthy humans: A double-blind, placebo-controlled dose-effect study. Psychopharmacology, 172(2), 145-156. doi:10.1007/s00213-003-1640-6

Hausner, M., \& Segal, E. (2016). LSD: Výzkum a klinická praxe za železnou oponou [The research and the clinical practice behind the Iron Curtain]. Prague, Czech Republic: Triton.

Hendricks, P. S., Thorne, C., Clark, C., Coombs, D. W., \& Johnson, M. W. (2015). Classic psychedelic use is associated with reduced psychological distress and suicidality in the United States adult population. Journal of Psychopharmacology, 29, 280-288. doi:10.1177/0269881114565653

Johansen, P.-Ø., \& Krebs, T. S. (2015). Psychedelics not linked to mental health problems or suicidal behavior: A population study. Journal of Psychopharmacology, 29(3), 270-279. doi: $10.1177 / 0269881114568039$

Johnson, M. W., \& Cosimano, M. P. (2012). Psilocybin in smoking cessation: A pilot study (ClinicalTrials.gov Identifier NCT01943994). Oxford, UK: Beckley Foundation.

Johnson, M., Garcia-Romeu, A. C., Cosimano, M. P., \& Griffiths, R. R. (2014). Pilot study of the 5-HT2AR agonist psilocybin in the treatment of tobacco addiction. Journal of Psychopharmacology, 28(11), 983-992. doi:10.1177/0269881114548296

Johnson, M. W., Richards, W. A., \& Griffiths, R. R. (2008). Human hallucinogen research: Guidelines for safety. Journal of Psychopharmacology, 22(6), 603-620. doi:10.1177/02698 81108093587

Kavenská, V., \& Simonová, H. (2014). Zkušenost s halucinogenní rostlinou ayahuasca $\mathrm{v}$ kontextu šamanského rituálu [Experience with hallucinogenic plant ayahuasca in the context of shamanic ritual]. Anthropologia Integra, 5(1), 51-63. doi:10.5817/AI2014-1-51

Krebs, T. S., \& Johansen, P.-Ø. (2012). Lysergic acid diethylamide (LSD) for alcoholism: Meta-analysis of randomized controlled trials. Journal of Psychopharmacology, 26(7), 994-1002. doi: $10.1177 / 0269881112439253$
Krebs, T. S., \& Johansen, P.-Ø. (2013). Psychedelics and mental health: A population study. PLoS One, 8(8), e63972. doi:10.1371/journal.pone.0063972

Kudrle, S. (2003). Úvod do bio-psycho-socio-spirituálního modelu závislosti [An introduction to the bio-psycho-socio-spiritual model of addiction]. In K. Kalina (Ed.), Drogy a drogové závislosti 1: Mezioborový př́stup [Drugs and drug addictions 1: An interdisciplinary approach] (pp. 90-95). Prague, Czech Republic: Úrad vlády České republiky.

Kumar, S. (2009). Psilocybin-assisted psychotherapy in the management of anxiety associated with stage IV Melanoma. (Clinical Trials.gov). Retrieved from http://www.clinicaltrials. gov/ct2/show/study/ NCT00979693?term=Psilocybin\&rank=1

Leonard, H. L., \& Rapoport, J. L. (1987). Relief of obsessivecompulsive symptoms by LSD and psilocin. American Journal of Psychiatry, 144(9), 1239-1240. doi:10.1176/ajp.144.9.1239b

Maclean, K., Johnson, M., \& Griffiths, R. (2011). Mystical experiences occasioned by the hallucinogen psilocybin lead to increases in the personality domain of openness. Journal of Psychopharmacology, 25(11), 1453-1461. doi:10.1177/026 9881111420188

Majic, T., Schmidt, T. T., \& Gallinat, J. (2015). Peak experiences and the afterglow phenomenon: When and how do therapeutic effects of hallucinogens depend on psychedelic experiences? Journal of Psychopharmacology, 29(3), 241-253. doi:10.1177/ 0269881114568040

Masters, R., \& Houston, J. (1970). Therapeutic applications of LSD and related drugs. In B. Aaronson \& H. Osmond (Eds.), The uses and implications of hallucinogenic drugs. London, UK: Hogarth Press.

Mithoefer, M., Wagner, M., Mithoefer, A., Jerome, L., \& Doblin, R. (2011). The safety and efficacy of $\pm 3,4$-methylenedioxymethamphetamine-assisted psychotherapy in subjects with chronic, treatment-resistant posttraumatic stress disorder: The first randomized controlled pilot study. Journal of Psychopharmacology, 25(4), 439-452. doi:10.1177/0269881110378371

Moreno, F. A., Wiegand, C. B., Taitano, E. K., \& Delgado, P. L. (2006). Safety, tolerability, and efficacy of psilocybin in 9 patients with obsessive-compulsive disorder. The Journal of Clinical Psychiatry, 67(11), 1735-1740. doi:10.4088/JCP. v67n1110

Mravčík, V., Chomynova, P., Grohmannová, K., Janíková, B., Leštinová, T. Z., Rous, Z., Kiššová, L., Kozák, J., Nechanská, B., Vlach, T., Černíková, T., Fidesová, H., Jurystová, L., \& Vopravil, J. (2016). Výroční zpráva o stavu ve věcech drog $v$ České republice v roce 2015 [Annual report on drug situation 2015 - Czech Republic]. Prague, Czech Republic: Úrad vlády České republiky.

Nichols, D. (2004). Hallucinogens. Pharmacology \& Therapeutics, 101(2), 131-181. doi:10.1016/j.pharmthera.2003.11.002

Nichols, D. (2016). Psychedelics. Pharmacological Reviews, 68(2), 264-355. doi:10.1124/pr.115.011478

Nutt, D., King, L., \& Philips, L. (2010). Drug harms in the UK: A multicriteria decision analysis. The Lancet, 376(9752) 1558-1565. doi:10.1016/S0140-6736(10)61462-6

Offord, D. R., \& Bennett, K. (2002). Prevention. In M. T. Rutter (Ed.), Child and adolescent psychiatry. Oxford, UK: Blackwell Science.

Okruhlicová, Š. (2012). Systém odměny a jeho role při vzniku závilosti [The reward system and its role in genesis of 
addiction] (Unpublished bachelor's thesis). Prague, Czech Republic: Univerzita Karlova v Praze.

Passie, T. (1997). Psycholytic and psychedelic therapy research: A complete international bibliography 1931-1995. Hanover, Germany: Laurentius Publishers.

Pokorný, V. (2016). Myslet z psychedelických zkušeností: Transdisciplinární interpretace [To thing from psychedelic experiences: A transdisciplinary interpretation]. Červený kostelec, Czech Republic: Pavel Mervart.

Ray, T. (2010). Psychedelics and the human receptorome. PLoS One, 5(2), e9019. doi:10.1371/journal.pone.0009019

Richards, W., Grof, S., \& Goodman, L. (1972). LSD-assisted psychotherapy and the human encounter with death. Journal of Transpersonal Psychology, 4, 121-150.

Ross, S. (2009). Psilocybin cancer anxiety study. New York University School of Medicine. Retrieved from http://www. clinicaltrials.gov/ct2/show/NCT00957359?term=Psilocybin\& rank $=4$

Roth, B. L., Palvimaki, E. P., Berry, S., Khan, N., Sachs, N., Uluer, A., \& Choudhary, M. S. (1995). 5-hydroxytryptamine2A (5-HT2A) receptor desensitization can occur without down-regulation. Journal of Pharmacology and Experimental Therapeutics, 275(3), 1638-1646.

Roubíček, J. (1961). Experimentální psychózy [Experimental psychoses]. Prague, Czech Republic: Státní zdravotnické nakladatelství [National Medical Publishing House].

Santos, R. G., Osório, F. L., Crippa, J. A., Riba, J., Zuardi, A. W., \& Hallak, J. E. (2016). Effects of ayahuasca, psilocybin and lysergic acid diethylamide (LSD): A systematic review of clinical trials published in the last 25 years. Therapeutic Advances in Psychopharmacology Review, 6(3), 193-213. doi:10.1177/2045125316638008

Sempere, A., Berenguer-Ruiz, L., \& Almazan, F. (2006). Chronic cluster headache: Response to psilocybin. Revista de Neurologia, 43(9), 571-572.

Sessa, B. (2005). Can psychedelics have a role in psychiatry once again? The British Journal of Psychiatry, 186(6), 457-458. doi:10.1192/bjp.186.6.457

Sewell, R. A., Halpern, J. H., \& Pope, H. G. (2006). Response of cluster headache to psilocybin and LSD. Neurology, 66(12), 1920-1922. doi:10.1212/01.wnl.0000219761.05466.43

Smart, R. G., \& Storm, T. (1964). The efficacy of LSD in the treatment of alcoholism. Quarterly Journal of Studies on Alcohol, 25, 333-338.

Stafford, P. (1997). Encyklopedie psychedelických látek [Psychedelic encyclopedia]. Prague, Czech Republic: Volvox Globator.

Strassman, R. (1984). Adverse reactions to psychedelic drugs: A review of the literature. The Journal of Nervous and Mental Disease, 172(10), 577-595. doi:10.1097/00005053198410000-00001

Studerus, E., Kometer, M., \& Hasler, F. (2011). Acute, subacute and long-term subjective effects of psilocybin in healthy humans: A pooled analysis of experimental studies. Journal of Psychopharmacology, 25(11), 1434-1452. doi:10.1177/ 0269881110382466
Taylor, M., Mackay, K., Murphy, J., McIntosh, A., McIntosh, C., Anderson, S., \& Welch, K. (2012). Quantifying the RR of harm to self and others from substance misuse: Results from a survey of clinical experts across Scotland. BMJ Open, 2(4). doi:10.1136/bmjopen-2011-000774

Thomas, G., Lucas, P., Capler, R., Tupper, K., \& Martin, G. (2013). Ayahuasca-assisted therapy for addictions: Results from a preliminary observational study in Canada. Current Drug Abuse Reviews, 6(1), 30-42. doi:10.2174/15733998 113099990003

Tylš, F. (2016). Elektroencefalografické změny v animálním serotonergním modelu psychózy-studium EEG konektivity ve vztahu $k$ chování [The electroencephalographic changes in animal serotonergic model of psychosis-the study of EEG connectivity in relation to behavior] (Dissertation PhD). Univerzita Karlova, Praha, 3. lékařská fakulta, Národní Ústav Duševního Zdraví, Czech Republic.

Tylš, F. (2017). The antidepressant effect of psychedelics and the role of neuroplasticity. Breaking Convention, London. Retrieved from https://www.youtube.com/watch? $\mathrm{v}=\mathrm{s} 3$ VeWbl1ZDU

Tylš, F., Páleníček, T., \& Horáček, J. (2014). Psilocybin Summary of knowledge and new perspectives. European Neuropsychopharmacology, 24(3), 342-356. doi:10.1016/j. euroneuro.2013.12.006

Tylš, F., Viktorinova, M., Prokopcova, D., Korcak, J., Horáček, J., \& Páleníček, T. (2016). Psilocybin administration in clinical trial: Acute effects, long-term effects and perception of music. Paper presented at ICPR conference, Amsterdam, The Netherlands.

van Amsterdam, J., Nutt, D., Phillips, L., \& van den Brink, W. (2015). European rating of drug harms. Journal of Psychopharmacology, 29(6), 655-660. doi:10.1177/0269881115581980

Viktorinová, M., \& Tylš, F. (2016). Nevědomé procesy lidské mysli: Poznatky z psychedelického výzkumu [Unconscious processes of human mind: Insights from psychedelic research]. Psychiatrie, 20(2), 100-107.

Vollenweider, F. X., \& Kometer, M. (2010). The neurobiology of psychedelic drugs: Implications for the treatment of mood disorders. Nature Reviews Neuroscience, 11(9), 642-651. doi:10.1038/nrn2884

Vollenweider, F. X., Vontobel, P., Hell, D., \& Leenders, K. L. (1999). 5-HT modulation of dopamine release in basal ganglia in psilocybin-induced psychosis in man - A PET study with [11C] raclopride. Neuropsychopharmacology, 20(5), 424-433. doi:10.1016/S0893-133X(98)00108-0

Watts, R., Krzanowski, J., Nutt, D., \& Carhart-Harris, R. (2017). Patients' accounts of increased 'connection' and 'acceptance' after psilocybin for treatment-resistant depression. Journal of Humanistic Psychology, 57(5), 520-564. doi:10.1177/ 0022167817709585

Winkler, P., \& Csémy, L. (2014). Self-experimentations with psychedelics among mental health professionals: LSD in the former Czechoslovakia. Journal of Psychoactive Drugs, 46(1), 11-19. doi:10.1080/02791072.2013.873158 